UDK 159.923.2-053.6

$316.728-053.6$

366-053.6

Pregledni rad

Primljeno: 22.2.2021.

\author{
Marina MATIĆ TANDARIĆ
}

Graditeljsko-geodetska škola Osijek, Hrvatska,m.matictandaric@gmail.com

\title{
ŽIVOTNI STILOVI ADOLESCENATA U POTROŠAČKI ORIJENTIRANOM DRUŠTVU
}

\begin{abstract}
Sažetak
Životni stilovi omogućuju stabilizaciju identiteta tijekom intenzivnog razvojnog razdoblja adolescencije te predstavljaju svojevrstan model ponašanja, stavova i orijentacija. Životni stil je sredstvo samoreprezentacije, karakterističan način ponašanja koji, osim bihevioralne komponente, uključuje i vrijednosti, identitet te resurse kojima pojedinac raspolaže. Postindustrijsko društvo karakterizira partikularnost mladenačkih stilova, a adolescenti imaju pristup i mogu participirati na globalnoj potrošačkoj sceni, gdje njihovi izbori postaju svojevrsne investicije. No njihovi izbori i obrasci potrošnje mogu biti izraz šireg strukturalnog iskustva i produkt manipulacije potrošačke industrije koja iznova nameće nove sadržaje kroz razne medije. Svrha rada je analizirati koncept životnoga stila $u$ adolescenciji te promotriti životne stilove adolescenata u potrošački orijentiranom društvu. Osim pružanja uvida u koncept i načine posredovanja životnih stilova, navedene spoznaje daju uvid $\mathrm{u}$ adolescentsku svakodnevnicu te mogu pridonijeti preventivnom $\mathrm{i} /$ ili odgojnom djelovanju odgojno-obrazovnih stručnjaka u kreiranju sadržaja u slobodno vrijeme. Ključne riječi: adolescenti; identitet; potrošačka kultura; životni stilovi
\end{abstract}

\section{ADOLESCENT LIFESTYLES IN A CONSUMER DRIVEN SOCIETY}

\begin{abstract}
Lifestyle enables identity stabilization during the intense developmental period of adolescence, and it presents a specific model of behaviour, attitudes and orientations. A lifestyle is a means of self-representation, a characteristic manner of conduct that, aside from its behavioural component, involves the values, identity and resources an individual possesses. The post-industrial society is characterized by a particularity of youth styles, and adolescents can access and participate in a global consumer scene where their choices become investments. However, their choices and patterns of consumption can be an expression of a broader structural experience and a product of manipulation of the consumer industry that continually imposes new content through various media. The aim of the paper is to analyse the adolescent lifestyle concept and examine adolescent lifestyles in a consumer driven society. In addition to providing insight into the concept and ways of mediating lifestyles, these insights provide a glimpse into the adolescents' everyday life and can contribute to the preventive and / or educational activities of educational professionals in creating leisure content.
\end{abstract}

Key words: adolescents; consumer culture; identity; lifestyles 


\section{Uvod}

Suvremeno društvo stavlja težište na osobno djelovanje i propagira preuzimanje odgovornosti za vlastite odluke. Životni stilovi jesu posljedica ili rezultat modernizacije (Richter, 2002), gdje društvo ,prestaje propisivati načine ponašanja i definirati što tko mora biti“ (Tomić-Koludrović i Leburić, 2002: 18). Životni stil se kreira, oblikuje i razvija na granici između individualne inicijative i društveno-kulturnih struktura te pritom odražava kulturu mladih (Miegel 1994). Mladi posebice tijekom adolescencije teže prepoznatljivosti, a stil pruža mogućnost ekspresije i distinkcije spram roditeljske kulture. Životni stil je sredstvo samoreprezentacije, karakterističan način ponašanja koji, osim bihevioralne komponente, uključuje i vrijednosti, identitet i resurse kojima pojedinac raspolaže. Osim što životni stilovi omogućuju stabilizaciju identiteta, oni predstavljaju i prostor u kojem mladi izgrađuju te oblikuju osobni i društveni identitet. Životni stilovi adolescenata pružaju uvid u njihove stavove, socijalne odnose, vrijednosti, načine djelovanja i posredovanja identiteta tijekom razdoblja odrastanja.

Iako se naglasak stavlja na osobno djelovanje, životni stilovi jesu rezultat socijalno-strukturalnih promjena te kulturnih i društvenih trendova. Neizvjesnost koju nose navedene promjene odrazile su se i na stabilnost životnih stilova. Adolescent više ne mora iskazivati pripadnost širem kolektivnom identitetu, već može posredovati svoj stil samostalno, bez posredništva (ne)formalnih grupa. Adolescenti imaju pristup i mogu participirati na globalnoj potrošačkoj sceni, gdje njihovi izbori postaju svojevrsne investicije. No njihovi izbori i obrasci potrošnje mogu biti izraz šireg strukturalnog iskustva i produkt manipulacije potrošačke industrije koja iznova nameće nove sadržaje i ponude. Stoga je svrha rada analizirati koncept životnoga stila $u$ adolescenciji te promotriti životne stilove adolescenata u potrošački orijentiranom društvu.

\section{Koncept životnog stila}

Stil se definira kao ukupnost prepoznatljivih karakteristika koje razlikuju osobu od drugog/drugih i čine koga prepoznatljivim (Miliša i Bagarić, 2012), kao jedinstven jezik koji je popraćen ,specifičnim zvukovima, fleksijom i sintaksom za izražavanjem života“ (Simmel i Frisby, 2004: 467) te kao ,„̌ivotni 
stav koji se izražava kroz izgled i ponašanje“ (Moore, 1994: 36). Stil u svojoj osnovi može biti (ne)formalne, deskriptivne, informativne i taksonomske prirode te se na temelju njega mogu donositi zaključci o pojedincu (Sobel, 1981). Stil nije samo pokazatelj subjektivnog svijeta pojedinca, nego i pokazatelj odnosa koji pojedinac ima s vlastitom sredinom.

Životni stil se pritom definira kao „dizajn života“ (Day, 2006: 219), aktivan, karakterističan i ekspresivan način života (Sobel, 1981), jedinstven model „egzistencije, izražavanja, obraćanja i samoostvarivanja pojedinca ili grupe“ (Fulgosi i Radin, 1982: 9), ukupni rezultat životnih odluka (Giddens, 1991) ili skup osobnih stavova i obrazaca ponašanja koji pripadaju kontekstu pojedinca (Chaney, 1996). Životni stil je, napominje Giddens (1991: 81), „rutinirana praksa" koja se iskazuje u stilu odijevanja, načinu prehrane i ponašanja te mjestima susreta s drugim pojedincima. Životni stil je, objašnjava Coleman (1960: 69), specifičan modus operandi koji objedinjuje obrasce reagiranja, promatranja, promišljanja, opažanja i djelovanja pojedinca. Pojedinac kreira relativno dosljedan stil stavljajući osobni pečat na aktivnosti, situacije, uloge i vlastiti kontekst (Coleman, 1960:69).

Životni stil se, prema Jensen (2007), analizira unutar četiriju okvira:

(1) globalnog - životni stil se promatra i definira u sferi globalne potrošnje

(2) strukturalno-nacionalnog - životni stil se definira kroz razne oblike potrošnje između nacija

(3) pozicijsko-supkulturnog - životni stil je pod utjecajem socijalizacijskih čimbenika (obitelji, vršnjaka, škole, društvenih pokreta i platformi) te predstavlja suvremenu supkulturnu inačicu

(4) individualnog - životni stil je oblik osobnoga identiteta, a izražava se kroz svakodnevnu rutinu.

Jensen (2007) nadalje opisuje životni stil kroz latinsku sintagmu modus vivendi te ga definira kao način života koji se, motiviran vrijednostima, ogleda u stavovima i odabirima pojedinca u slobodno vrijeme. Životni stil se promatra kao obrazac svakodnevnih aktivnosti, navika i izbora koji reflektiraju vrijednosti pojedinca i pod njihovim su utjecajem (Matić, 2018). Životni stilovi se 
neminovno vezuju uz koncept vrijednosti kao relativno trajnih vjerovanja koja utječu na ponašanja pojedinca. Osim motivacijske komponente, vrijednosti se posreduju i ostvaruju u okvirima životnoga stila (vidi Blunsdon, Reed, Blyton, Dastmalchian, 2010a; Miegel, 1994). Vrijednosti otkrivaju „gdje smo, što hoćemo, čemu se posvećujemo i težimo“ te stoga daju uvid u životni stil pojedinca (Petrović i Zotović, 2012: 48). Životni stilovi su produkt simbiotskog odnosa između vrijednosti i ponašanja (Miliša i Bagarić, 2012). Odnos između stila života i vrijednosti je uzajaman jer „kreirajući vlastitu životnu filozofiju“ kroz stil, pojedinci „,istovremeno bivaju određeni njome“ (Morris, 1973: 182).

Soininen i Merisuo-Storm (2010) smatraju da životni stil obuhvaća četiri dimenzije:

(1) bitak (eng. Being) se odnosi na obrasce ponašanja, socijalne odnose (druženja), odabrane sadržaje i (izvannastavne) aktivnosti u slobodnome vremenu

(2) posjedovanje (eng. Having) se odnosi na socioekonomski status (obrazovanje, zanimanje i mjesečna primanja roditelja), standard življenja te dostupnost raznim tipovima medija

(3) ljubav (eng. Loving) obuhvaća obiteljske i prijateljske odnose (strukturu, učestalost i kvalitetu odnosa)

(4) vrednovanje (eng. Valuing) se odnosi na vjerovanja (vrijednosti), interese $\mathrm{i}$ stavove pojedinca.

\section{Životni stil u adolescenciji}

Adolescencija, razdoblje života između djetinjstva i odrasle dobi, je razdoblje u kojem adolescenti ,prolaze kroz značajne biološke, psihološke i društvene transformacije“" (Natsuaki, Biehl i Xiaojia, 2009: 48). Prijelaz iz adolescencije u odraslu dob obilježen je značajnim razvojnim promjenama (Erikson, 1968), gdje adolescenti preispituju roditeljske vrijednosti te tragaju za novim vrijednostima i normama unutar okoline koja ih okružuje. Adolescenti streme novim socijalnim odnosima te traže potvrdu i razumijevanje vršnjaka (vidi Becht i sur., 2016; Becht i sur., 2017; Klarin, Proroković i Šimić-Šašić, 2010). Životni stilovi se često posreduju unutar grupe vršnjaka/prijatelja jer adolescent 
traži i dobiva potvrdu vlastita ponašanja. Jaka grupna identifikacija pomaže prilikom izgradnje identiteta, samopouzdanja, samopoštovanja, ali pomaže i u nošenju s brojnim izazovima koje nosi odrastanje. Vršnjačke skupine preuzimaju glavnu ulogu u procesu socijalizacije adolescenta jer su one izvor razumijevanja, suosjećanja i privrženosti (Car, 2013).

Životni stil, naglašava Allport (1961: 238), objedinjuje ,životne zadaće“ pojedinca, a njegov postupni razvoj je paralelan s rastućim osjećajem osobne autonomije. Životni stil povezuje psihosocijalni, osobni i ekonomski aspekt u svrhu razvijanja životnoga stila koji je primjeren vlastitim životnim okolnostima (Mlinarević, 2004). Kreiranjem i posredovanjem životnoga stila adolescent zadovoljava svoju potrebu za samoodređenjem i pripadanjem (Day, 2006). Osim toga, adolescent kroz životni stil, posredno ili neposredno, izražava ono što je i što postaje. Životni stil je vidljiv te predstavlja sredstvo kroz koje se adolescent predstavlja svijetu oko sebe. Životni stil pritom postaje sredstvo kroz koje adolescent komunicira o tome tko je, komu nalikuje i od koga se razlikuje (Gibbins i Reimer, 1999). Životni stilovi su odraz adolescentovih vrijednosti i stavova, a značenje i način posredovanja se kontinuirano redefinira unutar prijateljske ili vršnjačke grupe (Ingham, 1987). Berzano i Genova (2015) smatraju da životni stil obuhvaća specifičan i svojstven način ponašanja, uvjerenja i razmišljanja na temelju kojih se adolescenti povezuju ili diferenciraju.

Životni stil pruža uvid u realitet adolescenta, njegove vršnjačke odnose i način življenja, ali i načine izražavanja vlastita identiteta i osobnosti (Johansson i Miegel, 1992). Naime, adolescencija je, ističe Đuranović (2013), izazovno razdoblje u kojem pojedinac traga za sobom te aktivno formira svoj identitet. Izgradnja identiteta je ključan razvojni zadatak adolescencije (Erikson, 1968), a tijekom navedenoga razdoblja adolescent je u interakciji s roditeljima, nastavnicima i vršnjacima koji djeluju na njegovo samopoimanje i proces izgradnje identiteta (Luyckx, i sur., 2013). Suočeni s većim mogućnostima mladi razvijaju svijest o sebi, što ukazuje na dinamičnu prirodu identiteta. Za TomićKoludrović i Leburić (2002) identitet (self) nije statičan jer u interakciji s drugim subjektima adolescent uočava sličnosti i razlike u odnosu na druge te oblikuje svoje ja. Životni stil nije značajan samo za osobni, već i za društveni identitet jer omogućuje pojedincu stabilizaciju identiteta, povezuje osobe koje dijele 
isti životni stil i diferencira ih od onih koji mu ne pripadaju. Longitudinalno istraživanje Klimstra, Hale, Raaijmakers, Branje i Meeus (2010) na temu stabilnosti identiteta $u$ adolescenciji ukazalo je na njegovu duboku promjenjivost jer su ispitanici u dobi od 12 do 20 godina promišljali, istraživali i preispitivali svoje odluke. Životni stil pritom predstavlja sredstvo stabilizacije identiteta (Day, 2006), sredstvo posredovanja raznih identiteta (King, 2009) ili jedan od mogućih načina poigravanja identitetom (Chaney,1996). Životni stil također pruža simbolički okvir unutar kojeg adolescent kreira, eksperimentira i oblikuje identitet te pritom proživljava realnost koja nije pod konstantnim utjecajem odraslih. Spomenuti simbolički prostor postaje mjesto u kojem mladi mogu biti ono što jesu (Widdicombe i Wooffitt, 1995). Posredovanjem životnoga stila u afirmativnom, strukturiranom i stvaralački orijentiranom socijalnom okruženju mladi razvijaju sve aspekte ličnosti te postaju svjesni korisnici sadržaja u svim životnim sferama (Mlinarević, Miliša i Proroković, 2007).

Životni stil, napominje King (2009), je rezultat i pokazatelj promjenjive i fluidne ekspresije identiteta. Osim toga, sve naglašenija partikularnost življenja adolescenata otežava opisivanje jer ,su mu pripisana razna značenja izražena kroz brojne stilove, aktivnosti i obrasce ponašanja" (Debies-Carl, 2014: 28). Životni stil se može definirati kao način svakodnevnog ili rutinskog bivanja koji se reflektira u načinu prehrane, odijevanja te individualnim i društvenim obrascima djelovanja, no svaki oblik rutine podliježe promjenjivoj prirodi adolescentskog osobnog razvoja (Giddens, 1991).

Naime, životni stilovi jesu relativno stabilni obrasci ponašanja (TomićKoludrović i Leburić, 2002), no s obzirom na to da živimo u postmodernom društvu koje karakteriziraju tehnološke i kulturne promjene, životni stilovi su neminovno nestabilni i propusni (Roberts, 2006). Životni stil adolescenta je svojevrstan odgovor na kontinuirane društvene promjene (Miles, 2000), odgovor na sve više rastući broj izbora u modernim društvima (Giddens, 1991) te je aktivan i ekspresivan pokazatelj odnosa između adolescenta i društva (Miles, 2000). Osim što se nose $s$ težinom prelaska u odraslu dob, mladi to isto čine u društvu koje prolazi vlastite transformacije (Ilišin i Gvozdanović, 2020). Naime, prijašnji izvori sigurnosti, poput društvenih normi i institucija, koji su usmjeravali mlade na putu odraslosti, nestaju ili su u procesu preobrazbe. Mladi 
su, pojašnjavaju Ilišin i Gvozdanović (2020), ,prepušteni individualnoj potrazi za identitetom, integritetom, vlastitim životnim ciljevima i načinima njihova ostvarenja“, što naposljetku pogoduje primjeni raznih neetičkih taktika i strategija poput korištenja osobnih i obiteljskih veza i poznanstava u svrhu socijalnog napredovanja.

Nadalje, sve snažniji naglasak na individualizaciji života i samoregulaciji nosi sa sobom svojevrstan rizik (Beck, 1992) jer pojedinac mora preuzimati odgovornost za vlastite odluke i odabrani životni stil. Adolescent može unutar grupe prijatelja/vršnjaka posredovati određeni životni stil, no isto tako može iskazivati pripadnost određenom životnom stilu bez posredništva neformalne grupe. Mladi pojedinci dobivaju titulu ,stilskih surfera“ (Muggleton, 2000: 66) jer nakon što preuzmu i isprobaju određeni stil, oni ga odbacuju. Miješanje stilova je i prije bilo prisutno na adolescentskoj/mladenačkoj sceni, ističe Perasović (2002), te stoga životnim stilom imenujemo sve ono što sam pojedinac imenuje svojim životnim stilom.

\section{Životni stilovi adolescenata u potrošačkoj kulturi}

Životni stil ili medijski propagiran termin lifestyle promatra se kao životni projekt koji podrazumijeva stilsku osviještenost, individualizam i vlastiti izričaj (Featherstone, 2007: 84), a uređuje se kupovinom primjerenih indikatora stila. Svaki aspekt životnoga stila postaje ,način pričanja priče (...) način redizajniranja materijalne kulture na beskonačne načine“ (Chaney, 1996: 147). Pritom mjesto i način provođenja slobodnog vremena, odjeća, govor i tijelo predstavljaju načine izražavanje vlastite stilske posebnosti (Featherstone, 2007). Životni stil tada postaje materijalni oblik ekspresije identiteta (Wilska, 2002: 198), a potrošnja najočitije sredstvo izražavanja životnoga stila (Sobel, 1981). Santisi, Platania i Hichy (2014) se pritom pitaju je li bitnije imati ili bivati jer potrošnja postaje jedna od temeljnih aktivnosti pri konstrukciji identiteta. Postupno se gubi užitak koji dolazi iz praktične upotrebe kupljenoga predmeta/sadržaja ili aktivnosti, a jača prividni osjećaj ispunjenja koji dolazi iz pukog posjedovanja. Pojedinac posreduje osobni identitet kroz životni stil, a potrošnja održava njegovu stabilnost (Jensen, 2007). Potrošnja postaje središnja aktivnost u izgradnji osobnog, ali i društvenog identiteta jer se kroz prisvajanje predmeta ostvaruju 
odnosi među vršnjacima (Croghan, Griffin, Hunter i Phoenix, 2006). No Ilišin (2017) također ukazuje na problematičnost striktnog izjednačavanja konzumerizma i dokolice jer je izbor aktivnosti uvjetovan osobnim okolnostima te socijalizacijskim čimbenicima. Primjerice, Blunsdon i McNeil (2010b) smatraju da je prilikom analize životnoga stila potrebno uzeti u obzir sljedeće čimbenike: (1) vršnjake s kojima adolescent provodi vrijeme, (2) odabrane aktivnosti i vrijeme utrošeno na njih te (3) način potrošnje i važnost koju adolescent pridaje odnosima, aktivnostima i predmetima potrošnje.

Odabir životnoga stila postaje investicija u kojoj se čin kupnje promatra kao „potrošnja znakova“ na temelju kojih se adolescenti predstavljaju, povezuju ili distanciraju (Featherstone, 2007: 84). Životni stilovi se u postmoderni temelje na zadovoljstvu/hedonizmu, kreativnoj ekspresiji i stilskoj inovaciji (Muggleton, 2000). Kupovinu životnoga stila Shields (1992) poistovjećuje s karnevalom u kojem dolazi do inverzije potreba, što rezultira varijacijama selfa ili maski koje omogućuju povezivanje i isticanje. Životni stil, pojašnjava Božilović (2010), postaje investicija koja je obilježena simboličkom i društvenom vrijednošću te se bira i oblikuje na temelju vlastitog, ali i društveno-kulturnog ukusa. Potreba za posredovanjem određenog životnoga stila istovremeno potiče želju za potrošnjom, prihvaćanjem i praćenjem modnih, glazbenih i drugih trendova te oponašanjem idola (Wilska, 2002).

Odabrana roba predstavlja izvor zadovoljstva i sredstvo izražavanja vlastitog selfa pa se Belk (2000) pita je li pojedinac ono što posjeduje? Naime, spomenuta roba ima utilitarnu i interpersonalnu vrijednost te pomaže u kreiranju prijateljskih i inih odnosa (Richins, 1994). Croghan i sur. (2006) uočavaju važnost stila, odnosno glazbe i odjeće tijekom adolescencije kada adolescenti koriste stil kako bi se izrazili, povezali ili udaljili od vršnjaka. Stil postaje sredstvo konstrukcije osobnoga i društvenoga identiteta, a glazba, odjeća i ostali sadržaji potrošnje postaju oznake identiteta. Prisvajanjem robe, od stilskih predmeta do glazbenih i inih dijela, mladi se senzibiliziraju i postupno kreiraju i artikuliraju vlastitu životnu priču udaljenu od roditeljske kulture (Bennett, 2005).

Nadalje, suvremeni društveni trendovi i promjene stavili su dodatan naglasak na osoban izbor, želje i ukuse adolescenta, što rezultira pluralizacijom 
i diferencijacijom životnih stilova. Osim što napuštaju stilsku ujednačenost, mladi postaju aktivni eksperimentatori i potrošači raznih stilova. Mogućnost generalizacije otežava promjenjivost i neuhvatljivost životnih stilova, odnosno stilovi se pojavljuju, mijenjaju obrise ili nestaju. Svaki adolescent ili grupa vršnjaka/prijatelja koristi/konzumira glazbu, odjeću, sportske sadržaje, videoigrice itd. na drugačiji, svojstven način u okvirima slobodnoga vremena (vidi Crouch i Tomlinson, 1994; Fulgosi i Radin, 1982; Jenkins, 1983; King, 2009; Matić Tandarić, 2019; Roberts, 2006; Santisi i sur., 2014; Wilska, 2002). Santisi i sur. (2014: 100) životne stilove adolescenata s obzirom na potrošnju dijele na razborite, hedonističke i selektivne. Rezultati njihova istraživanja pokazali su da adolescenti kupuju određene (markirane) proizvode koji su u skladu s obiteljskim (roditeljskim) mogućnostima. Nadalje, autori primjećuju da se adolescenti identificiraju s određenim odjevnim markama (eng. brands) jer žele biti autentični, unikatni i ,zato što samo nekolicina ljudi posjeduje taj predmet“. Naposljetku, ispitanici kupuju određene predmete jer žele biti prihvaćeni unutar vršnjačke grupe. Životni stil ima ekspresivnu i distinktivnu dimenziju, a kupljena roba pritom može omogućiti adolescentu osjećaj autentičnosti i posebnosti (naspram drugih vršnjaka) te omogućiti pripadnosti grupi/društvu (Miles, 1998). Životni stil ukazuje na kompleksnost osobnoga i društvenoga identiteta jer adolescent koristi stil u svrhu (grupne) identifikacije. Tomić-Koludrović (1999) smatra da iako su mladi u Hrvatskoj upoznati s glazbom, modom i zapadnim trendovima, razlike u sferi potrošnje su prisutne jer njihovi izbori nisu rezultat osobnih htjenja.

Fulgosi i Radin (1982) identificirali su osam životnih stilova adolescenata: (1) intelektualno angažirani, (2) tradicionalni, (3) sport i tehniku, (4) konflikthe odnose s roditeljima, (5) neprilagođenost $i$ dosadu, (6) vjeru i političku neangažiranost, (7) ponašajnu nezavisnost i (8) dokoličarenje, potrošnju i pomodarstvo. Tomić-Koludrović i Leburić (2002) uočavaju šest tipova životnih stilova: (1) hedonističko-intelektualni, (2) dominantno-šminkerski, (3) površno-društveni, (4) tradicionalno-obiteljski, (5) društveno-svjesni, (6) dokoličarsko-šminkerski. Gvozdanović, i sur. (2019) razlikuju pet orijentacija ili stilova provođenja slobodnoga vremena: (1) orijentiranost prema spiritualnosti i društvenoj uključenosti, (2) zabavu i odmor, (3) zaokupljenost izlascima, (4) orijentiranost prema osobnom razvoju i (5) zaokupljenost videoigricama i sportom. 
S obzirom na stilove vezane uz potrošnju, Santisi i sur. (2014) razlikuju razboriti, hedonistički i selektivni stil. Rezultati pritom pokazuju da adolescenti kupuju robu poznatijih marki zbog osobne identifikacije s odabranom markom. Wilska (2002) razlikuje (1) hedonističko-materijalistički životni stil u kojem se orijentiranost materijalizmu očituje u sferi potrošnje vezane uz razne aktivnosti u slobodno vrijeme (izlaske, putovanja, sport, kulturne manifestacije), kupnju elektroničkih uređaja, aktivnosti vezane uz estetiku/izgled (odjeću, šminku i njegu tijela), (2) obiteljsko orijentirani stil koji se odnosi na potrošnju i aktivnosti koje su vezane uz obitelj, (3) deprivirani materijalistički stil koji karakterizira želja za potrošnjom (ugađanjem, kupovinom robe, putovanjima) te uvjerenje da viša financijska primanja donose boljitak i sreću, (4) intelektualno-mislilački stil (eng. highbrow) koji obuhvaća odlaske na kulturne manifestacije, slušanje klasične glazbe i orijentiranost humanitarnom radu, (5) ekološki i kritičan stil (eng. green and critical) je orijentiran očuvanju okoliša, a pojedinci imaju kritički stav prema potrošnji (iskazujući antimaterijalističke vrijednosti) te (6) štedljiv stil koji je orijentiran smanjenoj potrošnji nastaloj uslijed smanjenih financijski primanja.

Bennet (2003) zatim razlikuje pasivne (konzumiraju glazbene i druge sadržaje bez pretjeranog promišljanja) i aktivne tipove potrošača (svjesno preuzimaju i transformiraju materijalna dobra i pridaju im vlastita značenja). Autor ne umanjuje ulogu društva u kreiranju pasivnih potrošača, no istovremeno primjećuje mlade pojedince koji svjesno uzimaju sadržaje iz okoline i pridaju im vrijednosna značenja koja su kasnije implicitno posredovana kroz njihov stil. U istraživanju hip-hop i grime glazbene scene Dedman (2011) primjećuje razlike između aktivnih sudionika u kulturi i pasivnih konzumerista. Ispitanici prve skupine preuzimaju i oblikuju glazbene sadržaje prema svom ukusu, razgovaraju i razmjenjuju doživljaje s prijateljima te aktivno strukturiraju slobodno vrijeme odlaženjem na koncerte ili na druženja s ostalim ljubiteljima navedene glazbe. Akteri druge skupine preuzimaju i konzumiraju glazbene sadržaje bez pripisivanja određenog značaja. Oni slušaju glazbu koja je trenutno najpopularnija na glazbenim kanalima i ne osjećaju potrebu za dodatnom informiranošću o hip-hopu i grimeu. 
Stoga, životni stil u adolescenciji može biti oblik autentičnog izričaja, ali istovremeno može biti produkt manipulativne potrošačke industrije. Stavljajući naglasak na potrošačku socijalizaciju, „društveni identitet gubi sadržaj“, a životni stilovi postaju izbori i investicije koje se očituju u svim aspektima života i potrošnje (Tomić-Koludrović i Leburić, 2002: 18). Pojedinac, okružen mnoštvom mogućnosti, postupno počinje razvijati indiferentan stav ili eng. blase attitude jer se roba/predmeti/sadržaji pojavljuju, izmjenjuju i nestaju jednakom brzinom (Bauman, 2007). Indiferentnost prema znanju, prijateljima, zanimanju i generalno životnom usmjerenju nastupa zbog neprekidanog zatupljivanja diskriminatornog mišljenja (eng. blunting of discrimination). Brzina izmjene proizvoda i sadržaja na tržištu onemogućava diskriminaciju ili iskazivanje prednosti jednog sadržaja naspram drugog te vremenom postaju vrijednosno bezvrijedni (Bauman, 2005, 2007). Osim indiferentnosti, nezadovoljstvo postaje permanentno stanje jer stalna izmjena roba i sadržaja iznova stvara nove žudnje, želje i potrebe koje postaje nemoguće trajno zadovoljiti (Bauman, 2005).

Mladi sve više pasivno konzumiraju sadržaje koje im nudi potrošačka industrija te nisu aktivni u kreiranju novih sadržaja. Rezultati istraživanja Mlinarević, i sur. (2007) ukazali su na pasivnost adolescenata prilikom kreiranja sadržaja u slobodno vrijeme. Miles (1998: 111) ističe da se čak i sadržaj popularne pop-glazbe mijenja kako bi se standardizirao ukus adolescenta/ potrošača, čime on naposljetku postaje ,,pasivni subjekt programirane potrošnje“. Potrošačka industrija manipulira potrebama mladih kroz reklame, glazbene spotove i videozapise na društvenim mrežama u kojima zvijezde ostavljaju dojam autentičnosti i pristupačnosti, a istovremeno reklamiraju nove marke i predmete žudnje (Moore, 2005). Gangadharan (2015) ukazuje na sve rastući internetski trend Haul Girls u kojem adolescentice pokazuju robu koju su kupile u trgovačkim centrima ili su je dobile od raznih modnih kuća. Mediji, prema Hodkinson (2007), kontinuirano nude nove predmete potrošnje s kojima se adolescenti mogu tek privremeno identificirati i zadovoljiti. Shields (1992) doživljava medije kao generatore slika ili maski koje pojedinci preuzimaju i koriste u svrhu samoreprezentacije. Mjesta potrošnje, poput trgovačkih centara, predstavljaju prostor u kojem pojedinac kupuje identitet, a pritom i životni stil. Životni stil postaje „slobodno odabrana igra“ (Kellner, 1992: 158) jer „svatko može biti bilo tko" (Featherstone, 2007: 81). 
Prihvaćanjem trendova osigurava se pripadnost jednoj grupi, ali se istovremeno udaljava od drugih grupa ili pojedinaca (Miliša i Bagarić, 2012). Prema Clarke (2006) stil se promatra unutar grupe, odnosno njezine pozicije, unutarnjih odnosa i iskustava. Roba koja pristiže na komercijalno tržište je u svojoj prirodi diskriminatorna i stvara socijalne razlike. Materijalna ili simbolička dobra mladi pojedinac preuzima, oblikuje, transformira te prilagođava ovisno o sredini u kojoj živi. Miles (1998: 66) uočava da se adolescenti upoznaju, povezuju ili distanciraju kroz razgovore o određenim kupljenim predmetima. Autor ističe da je jedan od navedenih razloga zbog kojih su ispitanici kupovali određene predmete bila potreba za vršnjačkim prihvaćanjem i uklapanjem. Osim prihvaćanja, ispitanici su istaknuli da kroz kupnju i pokazivanje određenih predmeta „pokazuju tko su zapravo“. Autor primjećuje da su ispitanici kupovali malo drugačiju robu od ostalih vršnjaka jer su kroz to isticali svoju individualnost, ali su i dalje bili prihvaćeni unutar šire vršnjačke grupe. Miles (2003) smatra da se kroz potrošnju adolescenti diferenciraju te definira potrošnju kao način i sredstvo kroz koji se pojedinci ili grupe isključuju.

Croghan i sur. (2006) su nakon istraživanja na temu povezanosti identiteta, stila i potrošnje među adolescentima u dobi od 12 do 13 godina i od 16 do 17 godina uočili da dolazi do značajnih promjena kada je riječ o prioritetima vezanim uz potrošačke navike i stil. Nasuprot tomu, kada je riječ o prihvaćanju, popularnosti i posredovanju stila među vršnjacima, promjena u stavovima nije toliko izražena. Naime, ispitanici u dobi od 12 do 13 godina istaknuli su da bili ismijavani kada nisu nosili odjevne marke ili vrste odjevnih predmeta koje nosi vršnjaci ili starije generacije učenika. Umjesto da budu dalje ismijavani, ispitanici su se prilagodili i konformirali stilskim pravilima koja su nametnuli vršnjaci. Škola je za njih predstavljala mjesto na kojem je stil najvidljiviji i školska uniforma nije sprječavala daljnju diferencijaciju među vršnjacima s obzirom na stil. Iako je namjera škole i njezinih odgojno-obrazovnih stručnjaka bila spriječiti upravo te razlike, učenici su vrlo brzo pronašli način kako razviti i iskazati oznake stila (naušnicama, ogrlicama, satovima, tenisicama, torbama itd.). Ispitanici su osjećali pritisak jer su morali odabrati i kupiti određene odjevne predmete kako bi izbjegli podsmjehivanje, isključivanje ili izolaciju vršnjaka. Osim kupnje, ispitanici su morali pokazati autentičnost stilskih predmeta, što je utjecalo na njihovo samopoštovanje. Iako su znali da vršnjaci možda neće u 
svakom trenutku primijetiti kupljenu robu ili predmet, ispitanici su se osjećali manje vrijednima ako njihov odjevni predmet nije bio dovoljno skup ili cijenjen. Adolescenti u dobi od 16 do 17 godina pripisivali su značaj stilu, ali iz različitih razloga. Njihovi izbori su bili fleksibilniji, brinuli su o svom stilu jer su htjeli odati dojam ozbiljnosti i zrelosti, ali su htjeli i impresionirati ili privući osobe drugog spola. Autori zaključuju da su životni stilovi, kao aktivni oblici osobne ekspresije, u ovom istraživanju rezultat konformizma. Kao što rezultati pokazuju, adolescenti su posredovali određeni stil kako bi nalikovali ostalim vršnjacima i bili prihvaćeni unutar popularnih grupa vršnjaka. Autori upozoravaju na isključivost koja je prisutna prilikom posredovanja određenoga stila jer ono za njih predstavlja granicu na temelju koje se pojedinci ili grupe odvajaju.

Nakon komparativnoga istraživanja provedenog u privatnim i općim gimnazijama Piacentini i Mailer (2004) također zaključuju da kroz potrošnju adolescent posreduje i odražava self te da njegovo samopouzdanje varira ovisno o reakcijama okoline na kupljeno. Rezultati njihova istraživanja u skladu su s rezultatima istraživanja Croghan i sur. (2006) jer su se adolescenti na temelju kupljenih marki prepoznavali, povezivali ili distancirali. Obitelj, vršnjaci, škola i mediji kao temeljni socijalizacijski čimbenici predstavljaju, prema Belk (2000), izvore informacija na temelju kojih adolescent uči jezik ekspresivne potrošnje.

\section{Zaključak}

Životni stil kao svojstveni način ponašanja omogućava stabilizaciju identiteta tijekom izazovnog razdoblja adolescencije. Mladi tijekom adolescencije teže prepoznatljivosti, a životni stil pruža mogućnost ekspresije i distinkcije u odnosu na roditeljsku kulturu. No životni stilovi postaju nestabilni, fluidni i partikularni zbog kulturnih i društvenih trendova koje nameće potrošačka industrija.

Životni stilovi stoga mogu biti rezultat svjesnog djelovanja, ali isto tako mogu biti produkt potrošačke industrije koja utječe na stvaranje pasivnih potrošača koji stalno žude za novom robom, sadržajima i predmetima. Kupljeni proizvodi nose u sebi identifikacijsku vrijednost, što predstavlja velik izazov za 
školu i njezine stručnjake jer ne mogu svi adolescenti sudjelovati u činovima potrošnje.

S obzirom na to da se ne može pobjeći od sve naglašenije potrošačke kulture koja potiče pasivizaciju slobodnog vremena, pedagozi i nastavnici mogu pokušati integrirati vanjske utjecaje s ciljem stvaranja sadržaja s kojima bi se promicalo istraživanje i njegovalo kritičko promišljanje. Također je potrebno uvažiti prijedloge učenika kada je riječ o kreiranju izvannastavnih sadržaja i raznih programa za aktivno provođenje slobodnoga vremena. U razredima ili u okrugu škole mogu se organizirati radionice ili umjetničke manifestacije na kojima bi učenici bili aktivni kreatori sadržaja, a ne pasivizirani sudionici i potrošači. Navedene aktivnosti omogućile bi učenicima da se upoznaju, povežu i prihvate međusobne različitosti. Naposljetku, razvijanje životnog stila u afirmativnom i empatičnom okruženju omogućava kreativnost, stvaralaštvo i svestrani razvoj ličnosti.

\section{Literatura}

Allport, G. W. (1961). Pattern and Growth in Personality. New York: Holt, Rinehart and Winston.

Bauman, Z. (2005). Liquid Life. Cambridge: Polity Press.

Bauman, Z. (2007). Consuming life. Cambridge: Polity Press.

Becht, A. I., Nelemans, S. A., Branje, S. T., Vollebergh, W. M., Koot, H. M., Denissen, J. A. i Meeus, W. J. (2016). The quest for identity in adolescence: Heterogeneity in daily identity formation and psychosocial adjustment across 5 years. Developmental Psychology, 52(12), 2010-2021. DOI: 10.1037/dev0000245

Becht, A. I., Nelemans, S. A., Branje, S. T., Vollebergh, W. M., Koot, H. M. i Meeus, W. J. (2017). Identity uncertainty and commitment making across adolescence: Five-year within-person associations using daily identity reports. Developmental Psychology, 53(11), 2103-2112. DOI: 10.1037/dev0000374

Beck, U. (1992). Risk Society: Towards a New Modernity. London: SAGE Publications. Belk, R. W. (2000). Are We What We Own?. U A.L. Benson (Ur.), I shop, therefore I am: Compulsive buying and the search for self (str.77-97). Northvale, NJ: Jason Aronson. 
Bennett, A. (2003). The Use of 'Insider' Knowledge in Ethnographic Research on Contemporary Youth Music Scenes. U A. Bennett, M. Cieslik, S. Miles, (Ur.), Researching Youth (str.186-201). New York: Palgrave Macmillian.

Bennett, A. (2005). Culture and everyday life. London: SAGE.

Berzano, L., Genova, C. (2015). Lifestyles and Subcultures: History and a New Perspective. New York: Routledge.

Blunsdon B., Reed K., Blyton P., Dastmalchian A. (2010a). Social Change and Ways of Living: An Introduction. U P. Blyton, B. Blunsdon, K. Reed i A. Dastmalchian (Ur.), Ways of Living (str.1-16). London: Palgrave Macmillan.

Blunsdon, B., McNeil, N. (2010b). Personal Communities and Lifestyle: The Role of Family, Friends and Neighbours. U P. Blyton, B. Blunsdon, K. Reed i A. Dastmalchian (Ur.), Ways of Living (str.147-174). London: Palgrave Macmillan.

Božilović, N. (2010). Youth Subcultures and Subversive Identities. Facta Universitatis, Series: Philosophy, Sociology, Psychology and History, 9 (1), 45-58.

Car, S. (2013). Adolescencija 21. stoljeća: društvena uvjetovanost, temeljne karakteristike i pedagoški izazovi. Pedagogijska istraživanja, 10 (2), 285-294.

Chaney, D. (1996). Lifestyles. London, New York: Routledge.

Clarke, J. (2006). Style. U S. Hall, T. Jefferson, (Ur.), Resistance through Rituals. 2nd ed. (str.147-161). New York: Routledge.

Coleman, J. C. (1960). Personality dynamics and effective behavior. Chicago: Scott, Foresman.

Croghan, R., Griffin, C., Hunter, J. i Phoenix, A. (2006). Style Failure: Consumption, Identity and Social Exclusion. Journal Of Youth Studies, 9(4), 463-478.

Crouch, D.,Tomlinson, A. (1994). Collective self-generated consumption: leisure,space and cultural identity in late modernity. U: I. Henry, (Ur.), Leisure: modernity, postmodernity and lifestyles (str. 309-321). Eastbourne: Leisure Studies Association.

Day, G. (2006). Community and everyday life. New York: Routledge.

Debies-Carl, J. S. (2014). Punk Rock and the Politics of Place: Building a Better Tomorrow. New York: Routledge Routledge and Taylor \& Francis Group.

Dedman, T. (2011). Agency in UK hip-hop and grime youth subcultures - peripherals and purists. Journal Of Youth Studies, 5, 507-522.

Đuranović, M. (2013). Obitelj i vršnjaci u životu adolescenata. Napredak,154 (1-2), 31-46.

Erikson, E. H. (1968). Identity, youth and crisis. New York: W.W. Norton \& Company. 
Featherstone, M. (2007). Consumer Culture and Postmodernism. 2nd edition. London: Sage Publications Ltd.

Fulgosi, A., Radin, F. (1982). Stilovi života zagrebačkih srednjoškolaca. Zagreb: Naklada CDD.

Gangadharan, T. (2015). Social Network Sites as Evolving Subculture. Discourse, 3(1), 234-246.

Gibbins, R. J. i Reimer, B. (1999). The Politics of Postmodernity: An Introduction to Contemporary Politics and Culture. London: SAGE Publications Ltd.

Giddens, A. (1991) Modernity and self identity: self and society in the late modern age. Poilty Press, Cambridge.

Gvozdanović, A., Ilišin, V., Adamović, M., Potočnik, D., Baketa, N. i Kovačić, M. (2019). Youth study Croatia 2018/2019. Berlin: Friedrich-Ebert-Stiftung.

Hodkinson, P. (2007). Youth cultures: A critical outline of key debates. U P. Hodkinson, W. Deicke (Ur.), Youth Cultures: Scenes, Subcultures and Tribes (str.1-23). New York: Routledge and Taylor \& Francis Group.

Ilišin, V. (2017). Neke dimenzije slobodnog vremena mladih. U V. Ilišin i V. SpajićVrkaš (Ur.), Generacija osujećenih. Mladi u Hrvatskoj na početku 21. stoljeća (str. 293-316). Zagreb: Institut za društvena istraživanja.

Ilišin, V. i Gvozdanović, A. (2020). Klijentelizam i mladi u Hrvatskoj: komparativni uvid u odnos prema korištenju veza i poznanstava. U K. Kotarski i G. Radman (Ur.), Hrvatska u raljama klijentelizma. Politike, postupci i posljedice trgovanja institucionalnom moći (str. 115-137). Zagreb: Centar za demokraciju i pravo Miko Tripalo.

Ingham, R. (1987). Psychological contributions to the study of leisure- part two. Leisure Studies, 6 (1), 1-14.

Jenkins, R. (1983). Lads, Citizens and Ordinary Kids: Working Class Youth Lifestyles in Belfast. London: Routledge and Kegan Paul.

Jensen, M. (2007). Defining lifestyle. Environmental Sciences, 4 (2), 63-73.

Johansson, T. i Miegel, F. (1992). Do the right thing. Lifestyles and identity in contemporary youth culture. Stockholm: Almqvist \& Wiksell.

Kellner, D. 1992. Popular Culture and the Construction of Postmodern Identities. U S. Lash i J. Friedman (Ur.), Modernity and Identity (str.141-177). Oxford: Blackwell. King, K. H. (2009).Youth, Leisure, Lifestyles and Identities: Mountain Biking in the English Countryside (Neobjavljena doktorska disertacija). School of Environment and Technology,University of Brighton. 
Klarin, M., Proroković, A. i Šimić Šašić, S. (2010). Doživljaj prijateljstva i njegovi ponašajni korelati u adolescenata. Pedagogijska istraživanja, 7(1),7-22.

Klimstra, T. A., Hale, W. I., Raaijmakers, Q. W., Branje, S. T. i Meeus, W. J. (2010). Identity formation in adolescence: Change or stability?. Journal Of Youth And Adolescence, 39(2), 150-162. DOI: 10.1007/s10964-009-9401-4

Luyckx, K., Klimstra, T. A., Duriez, B., Van Petegem, S. i Beyers, W. (2013). Personal Identity Processes from Adolescence Through the Late 20s: Age Trends, Functionality, and Depressive Symptoms. Social Development, 22(4), 701-721.

Matić, M. (2018). Vrijednosne orijentacije i supkulturni stilovi adolescenata. U M.Nikolić, M.Vantić-Tanjić (Ur.), Unapređenje kvalitete života i djece (str.587-597). Tuzla: Udruženje za podršku i kreativni razvoj djece.

Matić Tandarić, M. (2019). High school students' leisure time activities. Odgojnoobrazovne teme (Educational issues), 2(3-4), 7-24.

Miegel, F. (1994). Seven lifestyles. U K.E.Rosengren (Ur.), Media effects and beyond: Culture, socialization and lifestyles (str. 212-232). London: Routledge.

Miles, M. (1998). Consumerism As a Way of Life. London:Sage.

Miles, S. (2000). Youth Lifestyles in a Changing World. Philadelphia: Open University Press.

Miles, S. (2003). Researching Young People as Consumers: Can and Should We Ask Them Why?. U A. Bennett, M. Cieslik, S. Miles, (Ur.), Researching Youth (str.170186). New York: Palgrave Macmillian.

Miliša, Z. i Bagarić, M. (2012). Stilovi ponašanja i vrijednosne orijentacije. Medianali, $12,68-104$.

Mlinarević, V. (2004). Stilovi slobodnog vremena srednjoškolaca Slavonije i Baranje. Pedagogijska istraživanja, 1 (2), 241-256

Mlinarević, V., Miliša, Z. i Proroković, A. (2007). Slobodno vrijeme mladih u procesima modernizacije - usporedba slavonskih gradova i Zadra. Pedagogijska istraživanja, $1,81-99$.

Moore, D. (1994). The Lads in Action: Social Process in an Urban Youth Subculture. Aldershot: Arena.

Moore, R. (2005). Alternative to what? Subcultural capital and the commercialization of a music scene. Deviant Behavior. 26(3), 229-252. DOI: 10.1080/01639620590905618 Morris, C. W. (1973). Varieties of human value. Chicago: University of Chicago Press. Muggleton, M. (2000). Inside Subculture The Postmodern Meaning of Style. Oxford and New York: Berg 
Natsuaki, M. N., Biehl, M. C. i Xiaojia, G. (2009). Trajectories of Depressed Mood From Early Adolescence to Young Adulthood: The Effects of Pubertal Timing and Adolescent Dating. Journal Of Research On Adolescence (Wiley-Blackwell), 19(1), 47-74.

Perasović, B. (2002). Sociologija subkultura i hrvatski kontekst. Društvena istraživanja, 2-3, 485-498.

Petrović, J. i Zotović, M. (2012). Adolescenti u Srbiji - u traganju za novim vrednostima. Teme, 36(1), 47-66.

Piacentini, M., Mailer, G. (2004). Symbolic Consumption in Teenagers Clothing Choices. Journal of Consumer Behaviour, 3(3), 251-262. DOI: https://doi.org/10.1002/ cb. 138

Richins, M. L. (1994).Valuing Things: Public and Private Meanings of Possessions. Journal of Consumer Research, 21 (3), 504-521. DOI: https://doi.org/10.1086/209414 Richter, R. (2002). Lifestyle and social Structure Processes of Individualization in Eastern European countries. Revija za sociologiju, 32(3-4), 169-180.

Roberts, K. (2006). Leisure in Contemporary Society. Oxfordshire:CABI.

Santisi, G., Platania, S. i Hichy, Z. (2014). A lifestyle analysis of young consumers: A study in Italian context. Young Consumers, 15(1), 94-104.

Shields, Rob (1992). Spaces for the Subject of Consumption. U R. Shields,R. (ur.), Lifestyle Shopping: The Subject of Consumption (str.1-21). New York: Routledge.

Simmel, G. i Frisby, D. (2004). The philosophy of money. London: Routledge.

Sobel, M.E. (1981). Lifestyle and Social Structure: Concepts, Definitions, Analyses. New York: Academic Press, Inc.

Soininen, M. i Merisuo-Storm, T. (2010). The life style of the youth, their everyday life and relationships in Finland. Procedia - Social and Behavioral Sciences, 2, 1665-1669.

Tomić-Koludrović, I. (1999). Skeptična generacija u protumodernizacijskom kontekstu. Politička misao, 36(3), 175-193.

Tomić-Koludrović, I. i Leburić, A. (2002). Sociologija životnog stila, prema novoj metodološkoj strategiji. Zagreb: Hrvatsko sociološko društvo, Jesenski Turk.

Widdicombe, S., Wooffitt, R. (1995).The Language of Youth Subcultures: Social Identity in Action. Hemel Hempstead: Harvester Wheatsheaf.

Wilska, T. (2002). Me - A Consumer? Consumption, Identities and Lifestyles in Today's Finland. Acta Sociologica (Taylor \& Francis Ltd), 45(3), 195-210. 